\title{
Perbandingan Ekuitas Merek Produk Natasha Skincare dengan Erha Skincare di Jember
}

\author{
Erina Mauidhatul Hasanah ${ }^{1 *}$, Budi Santoso², Haris Hermawan ${ }^{3}$ \\ 1,2,3 Fakultas Ekonomi dan Bisnis Universitas Muhammadiyah Jember
}

\section{A R T I C L E I N F O}

Article history:

Received 01 December 2019

Received in revised form

31 December 2019

Accepted 15 January 2020

Available online 26

February 2020

\section{Kata Kunci:}

Kesadaran Merek, Asosiasi

Merek, Persepsi Kualitas,

dan Loyalitas Merek.

Keywords:

Brand Awareness, Brand

Assosiation, Perceived

Quality, and Brand Loyalty

\begin{abstract}
A B S T R A K
Tujuan yang hendak dicapai dalam penelitian ini untuk mengetahui perbedaan antara Ekuitas merek Natasha Skincare dengan Erha Skincare pada konsumen pengguna Natasha Skincare dengan Erha Skincare di Jember. Metode yang digunakan untuk mengukur ekuitas merek menggunakan 4 dimensi yaitu, Kesadaran Merek, Asosiasi Merek, Persepsi Kualitas, dan Loyalitas Merek. Sampel yang digunakan dalam penelitian ini sebanyak 80 Responden. Pengumpulan data menggunakan penyebaran kuisioner. Metode analisis deskriptif kuantitatif, Uji beda T-test. Hasil dari penelitian dari empat variabel ekuitas merek terdapat perbedaan.
\end{abstract}

\section{A B S T R A C T}

The achieved purpose of this research was to know the difference between Natasha Skincare's brand equity with Erha Skincare's brand equity on Nataha Skincare's consumen and Erha Skincare consumen in Jember. the used method to survey the brand equity were using 4 dimensions there were, brand awareness, brand association, perceived quality, and brand loyalty. The sample of this research were 80 respondents. The collected data was spreading of questionnaire. The analysis method was quantitative description, different test of T-test. The result of the research from those four variables of brand equity, there was a difference.

\footnotetext{
* Corresponding author.

E-mail addresses: erina11@gmail.com (Erina Mauidhatul Hasanah)
} 


\section{Pendahuluan}

Lepas dari perhatian dan jarang diungkapkan, ternyata industri kosmetik di Indonesia berkembang pesat dari tahun ke tahun, dan kini mulai diperhatikan oleh berbagai pihak. Sebut saja Beauty Market Survey (BMS), menggunakan data dari Nielsen dan Euro Monitor, melaporkan bahwa nilai industri kosmetik Indonesia diperkirakan mencapai angka 36 triliun rupiah (USD \$2,7 billion) pada tahun 2016 atau meningkat 12 persen dibandingkan tahun sebelumnya (Indonesia-Investment, 2017). Kosmetika adalah bahan atau sediaan yang digunakan pada bagian luar tubuh manusia atau gigi dan mukosa mulut terutama untuk membersihkan, mewangikan, mengubah penampilan dan/atau memperbaiki bau badan atau melindungi atau memelihara tubuh pada kondisi baik. (Menteri Kesehatan RI, 2010). Berdasarkan data Kementerian Perindustrian (2016), pertumbuhan pasar industri ini rata-rata mencapai 9,67\% / tahun dalam 6 tahun terakhir (2009-15). Diperkirakan market size pasar kosmetik sebesar Rp. 46,4 triliun di tahun 2017 ini. Dengan jumlah tersebut, Indonesia merupakan potential market bagi para pengusaha industri kecantikan baik dari luar maupun dalam negeri (Sigma Research, 2017). Ekspornya pun tergolong tinggi, yaitu mencapai USD818 juta (Rp11 triliun) pada tahun 2015 (Manufacturindo, 2016). Pertumbuhan industri kosmetik diduga disebabkan oleh beberapa factor pemicu, seperti meningkatnya gaya hidup dan kesadaran masyarakat wanita untuk memperhatikan penampilan dan mempercantik diri. Berikutnya jumlah penduduk sekitar 255 juta jiwa, dengan hampir setengahnya penduduk perempuan, menjadikan Indonesia pasar yang menjanjikan bagi perusahaan kosmetik. Kemudian dengan seiring tumbuhnya populasi pria yang tergolong pada kelompok metroseksual, produsen kosmetika mulai melakukan inovasi untuk masuk ke segmen ini.

Itulah sebabnya mengapa CosmeticDesignAsia.com memperkirakan bahwa Indonesia akan menjadi the top 10 global pasar kosmetik perawatan kulit (US Commercial Service, 2016). Pemerintah pun memasukan industri ini dalam rencana prioritas pengembangan industri nasional hingga tahun 2019. Alasannya, pertama, karena industri kosmetik diposisikan sebagai industri subtitusi impor, yaitu karena sebagian besar bahan bakunya masih diimpor. Kedua, adalah dalam rangka meningkatkan kesem patan kerja bagi masyarakat local. Industri kosmetik termasuk industri padat karya, dan selama ini diperkirakan mampu menyerap 75.000 tenaga kerja langsung dan 600.000 tenaga kerja tidak langsung (Manufacturindo, 2016). Pertumbuhan subsector industri kosmetik di Indonesia tidak ayal lagi banyak mengundang new entry, baik dari luar maupun dalam negeri sendiri. Saat ini diperkirakan terdapat 760 perusahaan kosmetik yang tersebar di Indonesia (Manufacturindo, 2016), dan sampai dengan tahun 2012 telah terdaftar di pemerintah sekira 9.000 jenis produk kosmetik (Cekindo, 2016). Karena pasar kosmetik di Indonesia sangat prospektif, maka masuknya produk kosmetik impor pun tidak dapat dihindari. Hasil riset yang dilakukan oleh Nielsen, berdasarkan data penjualan produk kecantikan pada triwulan III 2015, $48 \%$ konsumen menyukai kosmetik merek global, $36 \%$ memilih produk local, dan $16 \%$ sisanya tidak memiliki preferensi apapun (Rahayu, 2017).

Seiring dengan berkembangnya pengetahuan dan teknologi, maka kebutuhan terhadap kecantikan terus berkembang, sejalan dengan kebutuhan untuk mempercantik diri pun kini menjadi prioritas utam1 a kaum perempuan dalam menunjang penampilan seharihari. Kaum perempuan akan selalu berusaha untuk mengubah penampilan atau mempercantik diri dengan menggunakan kosmetika. Keinginan untuk mempercantik diri secara berlebihan, salah pengertian akan kegunaan kosmetik, menyebabkan kaum perempuan sering berbuat kesalahan dalam memilih dan menggunakan kosmetik tanpa memperhatikan kondisi kulit dan pengaruh lingkungan. Hasil yang didapatkan tidak membuat kulit menjadi sehat dan cantik, tetapi malah terjadi berbagai kelainan kulit yang disebabkan oleh penggunaan kosmetika tersebut. Gaya hidup yang kini terjadi pada masyarakat khususnya kaum perempuan baik di kota maupun di desa, membuat para produsen kosmetik berlomba-lomba mempromosikan produknya, selain melalui iklan, mereka tidak segansegan memangsa konsumennya dalam ketidak tahuan mereka, sehingga banyak kaum perempuan yang terjebak dalam dilemma ketidak mengertian mereka tentang konsmetika tersebut secaru menyeluruh (Pangaribuan, 2017).

Kosmetika adalah bahan atau sediaan yang dimaksudkan untuk digunakan pada bagian luar tubuh manusia (epidermis, rambut, kuku, bibir dan organ genital bagian luar) atau gigi dan membran mukosa mulut terutama untuk membersihkan, mewangikan, mengubah penampilan dan atau memperbaiki bau badan atau melindungi atau memelihara tubuh padakondisi baik (BPOM RI, 2011). Kosmetika saat ini sudah menjadi kebutuhan penting bagi manusia. Kosmetika tidak hanya digunakan untuk fungsi estetika, akan tetapi berperan dalam penyembuhan dan perawatan kulit. Meski bukan merupakan kebutuhan primer, namun kosmetika merupakan salah satu produk yang digunakan rutin dan terus-menerus oleh manusia. Oleh karena itu keamanan kosmetika dari bahanbahan berbahaya perlu diperhatikan (Lisnawati, 2016). 
Kosmetik menurut Food and Drug Administration (FDA) merupakan produk yang digunakan pada kulit untuk tujuan membersihkan, mempercantik, meningkatkan daya tarik, atau memperbaiki penampilan (FDA, 2012). Produk kosmetik tidak hanya digunakan bagi orang dewasa tetapi juga untuk anak-anak dan orang usia lanjut (Felicia, 2013). Berdasarkan hasil riset lembaga informasi dan pengukuran global Nielsen pada tahun 2013 terjadi peningkatan konsumsi kosmetik di wilayah Indonesia. Di perkotaan terjadi peningkatan sebanyak 9,4\% dari 554 miliar menjadi 606 miliar sedangkan di pedesaan terjadi peningkatan sebanyak 27,5\% dari 64 miliar menjadi 82 miliar. Peningkatan konsumsi kosmetik di Indonesia ini sangat menjanjikan sehingga banyak produsen membuat produk kosmetik dalam berbagai bentuk sediaan serta kandungan bahan kimia. Badan Pengawas Obat dan Makanan menyebutkan beberapa kriteria produk kosmetik yang dapat dikategorikan aman meliputi adanya kemasan, label, izin edar, kegunaan dan cara penggunaan, tanggal kadaluarsa, serta tidak terkandungnya bahan kimia berbahaya (BPOM, 2016a).

Pada semester II tahun 2016, Badan Pengawas Obat dan Makanan (BPOM) menemukan 39 jenis kosmetik yang meliputi 25 merk produk lokal dan 14 merk produk impor yang mengandung bahan kimia berbahaya, didominasi oleh produk kosmetik dekoratif (misal bedak, lipstik, pemerah pipi, eye shadow, dan lain-lain) dan produk perawatan kulit (misal pelembab, tabir surya, facial wash, toner, dan lain-lain). Mayoritas produk mengandung bahan pewarna merah K3 dan K10 (rhodamin B) sebanyak 46,16\%, diikuti produk kosmetik yang mengandung hidrokinon dan merkuri masing-masing sebanyak 17,95\%. Selain itu, ditemukan juga kosmetik yang mengandung klindamisin dan teofilin (BPOM, 2016b). Berdasarkan Peraturan Kepala BPOM nomor 18 tahun 2015 tentang persyaratan teknis bahan kosmetik, bahan kimia berbahaya dalam produk kosmetik dibedakan menjadi dua, yaitu bahan kimia berbahaya yang dilarang dan bahan kimia berbahaya yang diperbolehkan digunakan dengan pembatasan dalam penggunaannya pada produk kosmetik. Bahan kimia berbahaya yang dilarang, yaitu merkuri, pewarna merah K3 dan K10 (rhodamin B), dan asam retinoat sedangkan bahan kimia berbahaya yang diperbolehkan digunakan dengan pembatasan dalam penggunaannya pada produk kosmetik, yaitu hidrokinon dengan batas maksimum penggunaan $0,02 \%$, formaldehid dengan batas maksimum penggunaan $5 \%$, triclosan dengan batas maksimum penggunaan $0,3 \%$, dan resorsinol dengan batas maksimum penggunaan 0,5\%. Penggunaan bahan kimia berbahaya pada produk kosmetik dapat menimbulkan berbagai masalah kesehatan yang serius. Pewarna merah K3 dan K10 (rhodamin B) bersifat karsinogenik dapat memicu kanker (Cahyadi, 2009) (Nurhan, 2017).

Perawatan kecantikan saat ini menjadi kebutuhan bagi setiap orang yang menginginkan kulit bersih dan cantik. Sudah menjadi hal biasa bagi kaum laki-laki dan terutama wanita yang melakukan perawatan. Gaya hidup yang menuntut untuk lebih memperhatikan penampilan, maka dari itu perawatan kulit menjadi hal yang sangat penting. Berikut data persaingan klinik kecantikan yang sudah memiliki nama di Indonesia :

Tabel 1. Pangsa Pasar Persaingan Klinik Kecantikan

\begin{tabular}{|c|c|c|}
\hline No & Nama Klinik Kecantikan & Pangsa Pasar (\%) \\
\hline 1 & Natasha Skincare & $47 \%$ \\
\hline 2 & Erha Skincare & $19 \%$ \\
\hline 3 & Larissa & $8 \%$ \\
\hline 4 & Anita salon & $7 \%$ \\
\hline 5 & Medisa & $5 \%$ \\
\hline 6 & Evamulia & $5 \%$ \\
\hline 7 & Miracle & $3 \%$ \\
\hline 8 & House of skin & $2 \%$ \\
\hline \multirow[t]{2}{*}{9} & Lainnya & $1 \%$ \\
\hline & Total : & $100 \%$ \\
\hline
\end{tabular}

Sumber : Nursukmawati, 2013

Tabel 2. Jumlah Pengguna Natasha Skincare dan Erha Skincare di Jember Tahun 2017-2019

\begin{tabular}{ccccccccc}
\hline Tahun & \multicolumn{3}{c}{ Pengguna Natasha Skincare } & \multicolumn{3}{c}{ Pengguna Erha Skincare } \\
\cline { 2 - 9 } & Pria & $\%$ & Wanita & $\%$ & Pria & $\%$ & Wanita & $\%$ \\
2017 & 200 & $40,2 \%$ & 297 & $59,8 \%$ & 169 & $43 \%$ & 223 & $57 \%$ \\
2018 & 276 & $47 \%$ & 312 & $53 \%$ & 253 & $46 \%$ & 298 & $54 \%$ \\
\hline
\end{tabular}




\begin{tabular}{lllllllll}
2019 & 289 & $42,5 \%$ & 391 & $57,5 \%$ & 279 & $46,7 \%$ & 318 & $53,3 \%$ \\
\hline
\end{tabular}

Sumber : wawancara pihak Natasha Skincare dan Erha Skin

\section{Metode}

Menurut Sugiyono (2013:389) populasi adalah wilayah generalisasi yang terdiri atas objek maupun subjek yang mempunyai karakteristik dan kualitas yang dipelajari oleh peneliti lalu ditarik kesimpulannya. Berdasarkan pendapat para ahli, populasi dalam penelitian ini adalah populasi yang sifatnya homogen. Dan populasi pada penelitian ini yaitu masyarakat yang menggunakan skincare.

Menurut Sugiyono (2013:389) sampel merupakan sebagian dari populasi tersebut. Jika populasi tidak diketahui, jumlah sampel minimal lima kali dari jumlah butir pertanyaan yang terdapat pada kuisioner variabel bebas yang terdiri dari total pertanyaan 16 indikator. Sehingga besar sampel yang diteliti 16X5=80 responden (Hair,2014). Metode pengambilan sampel yang digunakan dalam penelitian ini yaitu purposive sampling, yang mana pengambilan elemennya dimasukkan dalam sampel yang dilakukan dengan sengaja, dengan catatan sampel tersebut representative atau mewakili populasi yang dikemukakan oleh Arikunto 2009.

\section{Hasil dan pembahasan}

1. Analisa Brand Awareness antara Natasha Skincare dengan Erha Skin

Dalam penelitian ini terdapat perbedaan kesadaran merek Erha Skin lebih unggul dari Natasha Skincare. Hasil pengolahan dan analisis skor yang telah dilakukan. Hal ini dibuktikan dengan nilai sig.2tailed adalah $.809<0,05$ dan nilai tengah Brand Awareness memiliki nilai yang berbeda yaitu 2.899 dan 2.877. perbedaan ini disebabkan karena responden saat ditanya mengenai merek skincare yang pertama muncul dalam benak mereka yaitu Erha Skin. Hasil penelitian ini searah dengan hasil penelitian sebelumnya yang dilakukan oleh Wati (2016), bahwa ada perbedaan brand awareness antara nivea dengan citra. Perbedaan ini bisa disebabkan karena brand Erha Skin telah dikenal jauh lebih lama oleh para pengguna skincare, sehingga menjadi top of mind dikategori skincare. Hal ini sesuai dengan teori bahwa salah satu faktor yang mempengaruhi brand awareness dari suatu produk adalah karena perusahaan telah memasarkan brand tersebut dalam waktu yang lama (Humdiana, 2005).

\section{Analisa Brand Assosiation Natasha Skincare dengan Erha Skin}

Dalam penelitian ini terdapat perbedaan, hasil pengolahan dan analisis skor yang telah dilakukan, diperoleh bahwa ada perbedaan Brand Assosiation, dimana Erha Skin lebih unggul dari Natasha Skincare. Hal ini dibuktikan dengan nilai sig.2tailed $.679<0,05$ dan nilai tengah Brand Assosiation memiliki nilai berbeda yaitu 2.183 dan 2.053. Perbedaan ini disebabkan karena responden lebih setuju Erha Skin memiliki image yang baik yang dapat menjadi kekuatan tersendiri bagi Erha Skin. Hasil penelitian ini searah dengan hasil penelitian sebelumnya yang dilakukan oleh Wati (2016) bahwa ada perbedaan brand association antara nivea dengan citra.

\section{Analisa Brand Perceived Quality Natasha Skincare dengan Erha Skin}

Dalam penelitian ini terdapat perbedaan, hasil pengolahan dan analisis skor yang telah dilakukan, diperoleh bahwa ada perbedaan Perceived Quality, dimana Erha Skin lebih unggul dari Natasha Skincare. Hal ini dibuktikan dengan nilai sig.2tailed $.513<0,05$ dan nilai tengah Perceived Quality memiliki nilai berbeda yaitu 1.911 dan 1.709. Perbedaan ini disebabkan karena responden lebih menyukai perawatan dari Erha Skin karena menggunakan teknologi yang canggih dan memiliki kualitas yang bagus. Hasil penelitian ini searah dengan hasil penelitian sebelumnya yang dilakukan oleh Wati (2016) bahwa ada perbedaan perceived quality antara nivea dengan citra.

\section{Analisa Brand Loyalty Natasha Skincare dengan Erha Skin}

Dalam penelitian ini terdapat perbedaan, hasil pengolahan data dan analisis skor yang telah dilakukan, diperoleh bahwa ada perbedaan Brand Loyalty, dimana Erha Skin lebih unggul dari Natasha Skincare. Hal ini dibuktikan dengan nilai sig.2tailed .165 < 0,05 dan nilai tengah Brand Loyalty memiliki nilai yang berbeda yaitu 4.001 dan 3.273. Perbedaan ini disebabkan karena Erha Skin mampu memberikan kepuasan kepada konsumennya secara konsisten. Loyalitas tidak terbentuk secara instan dan pengalaman selama menggunakan brand tersebut akan menjadi hal mendasar yang mendorong konsumen untuk terus melakukan pembelian ulang. Menurut Humdiana (2005), menyatakan bahwa suatu basis pelanggan yang puas dan suka akan suatu merek tertentu dapat menimbulkan keyakinan bagi pelanggan maupun calon pelanggan. Kelompok pelanggan yang puas akan memberikan suatu citra bahwa 
merek tersebut merupakan produk yang diterima luas, berhasil, dan mampu memberikan nilai tambah bagi konsumen sehingga tercipta loyalitas terhadap suatu merek.

\section{Simpulan dan saran}

Berdasarkan hasil analisis dan pembahasan diatas, maka dapat disimpulkan sebagai berikut :

a. Kesadaran merek ( Brand Awareness ) menunjukkan adanya perbedaan yang signifikan antara Natasha Skincare dengan Erha Skin

b. Asosiasi merek ( Brand Association ) menunjukkan adanya perbedaan yang signifikan antara Natasha Skincare dengan Erha Skin

c. Persepsi kualitas Merek ( Brand Perceived Quality) menunjukkan adanya perbedaan yang signifikan antara Natasha Skincare dengan Erha Skin

d. Loyalitas merek ( Brand Loyalty) menunjukkan adanya perbedaan yang signifikan antara Natasha Skincare dengan Erha Skin

e. Keterbatasan dari penelitian ini yaitu adanya jawaban responden yang didapati kurang tepat dapat dibuktikan pada salah satu variabel yang nilai $R$ hitung 0,237 lebih kecil dari $R$ tabel 0,26 sehingga mengakibatkan data tidak valid pada variabel tersebut. Diharapkan bagi peneliti selanjutnya untuk lebih menambah jumlah sampel dalam mengantisipasi data untuk lebih akurat.

\section{Daftar Rujukan}

A.Aaker, David. 2010. Asosiasi Merek. Jurnal Management

Feyrene \& Lee, G. C. 2011. Customer-based Brand Equity: A Literatur Review. Journal of Arts Sciene \& Commerce. 11(1): 33-42.

Ghozali, Imam. 2013. Aplikasi Analisis Multivarian dengan Program IBM SPSS 21 Update PLS Regresi. Universitas Diponegoro. Semarang.

Kotler, \& Amstrong. 2012. Konsep Merek dalam Produk. Journal of Business and Management.

Kusdyah, Ike. Persepsi Harga, Persepsi Merek, Persepsi Nilai, dan Keinginan Pembelian Ulang Jasa Clinic Kesehatan ( Studi Kasus pada Erha Clinic Surabaya ). Jurnal Manajemen Pemasaran. Vol.7, No.1, April 2012.

Lisnawati, Deni. 2016. Tingkat Pengetahuan Dan Persepsi Bahaya Kosmetika Yang Mengandung Bahan Pemutih Di Smk Negeri 4 Yogyakarta . Jurnal media Farmasi Vol. 13 No. 1 Maret 2016

Nainglon, Marsia.2018. Analisis Perbandingan Ekuitas Merek Kartu Seluler Merek Simpati dan XL Prabayar, Vol.3 No.1, Jurnal Digest Marketing

Nurhan, Ahmad Dzulfikri. 2017. Pengetahuan Ibu-Ibu Mengenai Kosmetik Yang Aman Dan Bebas Dari Kandungan Bahan Kimia Berbahaya . Jurnal Farmasi Komunitas Vol. 4, No. 1, (2017)

Pangaribuan, Lina. 2017. Efek Samping Kosmetik Dan Penangananya Bagi Kaum Perempuan . Jurnal Keluarga Sehat Sejahtera Vol. 15 (2) Desember 2017

Purwanto, L. Putri. \& Wardhana, Aditya. Analisis Perbandingan Atribut Produk Kosmetik All In One Face Base By The Body Shop Dengan Face It Radiance Powder By The Face Shop. e-Proceeding of Management. Vol.3, No.1, April 2016.

Putra, Praman. 2018. Analisis Perbandingan Brand Equity Produk Indocafe dengan Good Day, Vol.7, Denpasar : E-Jurnal manajemen Unud.

Rahayu, Yulianita. 2017. Analisis Kesadaran dan Loyalitas Merek Kosmetik Herborist. Jurnal Ekubis Volume 2, No. 1, September 2017, Issn: 2541-1950 
Simamora, 2010. Analisis Elemen-elemen Ekuitas Merek

Wati, Lisma \& Suharno \& Saida Zainurossalamia Z.A. 2016. Analisis Perbandingan Brand Equity pada Produk Lotion Merek Nivea dengan Merek Citra. JIMM, Vo.1, No.1, 2016. 